\title{
Mechanical properties of different bamboo species
}

\author{
Dinie Awalluddin ${ }^{1}$, Mohd Azreen Mohd Ariffin ${ }^{1,2^{*}}$, Mohd Hanim Osman ${ }^{1,2}$, Mohd Warid \\ Hussin ${ }^{1}$, Mohamed A. Ismail ${ }^{3}$, Han-Seung Lee ${ }^{4}$, and Nor Hasanah Abdul Shukor Lim ${ }^{1}$. \\ ${ }^{1}$ Faculty of Civil Engineering, Universiti Teknologi Malaysia, 81310 UTM Johor Bahru, Johor, \\ Malaysia. \\ ${ }^{2}$ Forensic Engineering Centre, Institute for Smart Infrastructure Innovative Construction, Faculty of \\ Civil Engineering, Universiti Teknologi Malaysia, 81310 UTM Johor Bahru, Johor, Malaysia \\ ${ }^{3}$ Department of Civil and Construction Engineering, Faculty of Engineering and Science, Curtin \\ University Sarawak, CDT 250, Miri 98009, Sarawak, Malaysia. \\ ${ }^{4}$ Department of Architectural Engineering, Hanyang University, 1271 Sa 3-dong, Sangrok-gu, Ansan \\ 426-791, Korea.
}

\begin{abstract}
Bamboo is a rapid renewable plant that has a fast growth rate as compared to trees, which increases its suitability to be used as a sustainable source for wood industry, especially in construction works. Due to the lack of understanding on bamboo properties, the utilization of bamboo in construction has always been neglected. This paper presents an investigation on the mechanical properties of four species of treated bamboos that are available in Malaysia, which include Bambusa Vulgaris, Dendrocalamus Asper, Schizostachyum Grande, and Gigantochloa Scortechinii. A mechanical testing was carried out in various parts along the culm of these bamboo species in order to examine the differences of their compressive strength and tensile strength. The strength development and moisture content of these bamboo species were also monitored at a five-month interval. The results showed that Bambusa Vulgaris, Dendrocalamus Asper, and Gigantochloa Scortechinii possess excellent mechanical properties in compression and tensile strength, which indicate a good quality to be used as a construction material. As bamboo offers promising advantages, thus, it is suitable to be used as a substitute in place of structural timber in construction, which indirectly facilitates the preservation of the global environment.
\end{abstract}

\section{Introduction}

Being classified as a grass member of a larger grass family [1], bamboo can be easily found in tropical and some temperate areas of the world.

\footnotetext{
* Corresponding author: mohdazreen@utm.my
} 
Bamboo has a nature form comprising a cylindrical pole with jointed stem known as a culm. There are over 1500 identified bamboo species in the world [2]. As one of the fastest growing plants, bamboo can reach a full height ranging from $15-30 \mathrm{~m}$ in a period of two to four months [3]. All bamboo species has a similar anatomy, which consists of nodes, internodes, and diaphragm as shown in Figure 1. Each species can be identified according to their root system, in which there are three known root systems including, sympodial, monopodial, and amphodial [4]. The thickness of a bamboo decreases along the height of the culm, while the fibres density increases from the bamboo culm's inner wall to outer wall.

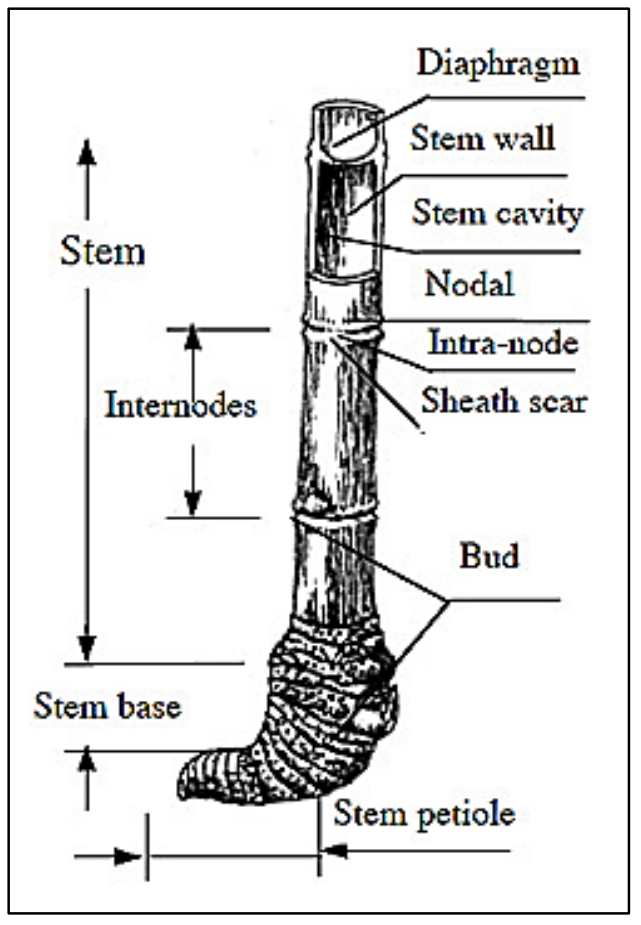

Fig.1 Bamboo anatomy

Bamboo forest has a higher harvest cycle, with up to four times of carbon density per hectare in comparison to spruce forest [5]. This means that bamboo can be harvested in a short period of time, in addition to having a high rate of carbon absorption as compared to timber. Recently, there is a growing interest in using bamboo as a construction material, in place of timber. In China, contractors have utilized bamboo as scaffoldings, while in Bali, bamboo is used to construct a Green School [6], where all structural components of the building is sourced from a local bamboo supplier. In contrast, in other developing country, the utilization of bamboo as a construction material is scarce, even with an abundance of bamboo source available. Lack of study concerning the mechanical properties of bamboo is known to be one of the factors that is associated with a low utilization of bamboo in construction.

The ability and capacity of bamboo to withstand the force applied onto it is very important. The strength and moisture content of the bamboo are among the most important factors, which determine both ability and capacity of full bamboo culm. Bamboo with a moisture content of $15 \%$ or lower tends to have good mechanical properties and is less vulnerable to fungus attack [7]. In determining the strength of bamboo, $12 \%$ of moisture content in air-dry condition has been regarded as a standard and reference [8]. In terms of 
durability, it varies according to species and age ranges. It is estimated that an untreated bamboo has a design life of approximately 10-15 years if it is stored appropriately, while a treated bamboo will have a much longer design life [9].

The strength of bamboos also depends on age ranges and species, which determines their suitability to be used in construction when they reach maturity age of around 3-4 years. In maturity, bamboos possess an optimum strength and are suitable to be used for heavy-duty applications. It has also been found that bamboos' compressive strength increases along their height, in addition to increasing compressive strength from the inner part to the outer part of their culm [10]-[13].

The aim of this research is to investigate on the mechanical properties of different species of local bamboos. This research is a part of an experimental work which focuses on the possibility of utilizing bamboo as a construction material.

\section{Materials and methods}

\subsection{Preparation of the bamboo}

There are four bamboo species involved in this research, which are sourced from Perak, Malaysia. Those four bamboo species include, Dendrocalamus Asper, Bambusa Vulgaris, Schizostachyum Grande, and Gigantochloa Scortechinii. These four bamboo species were selected and left to dry for about three weeks until the colour of the bamboos turned yellowish from their original colour. They were subsequently treated by using boric acid, in order to increase their durability and ability against fungus attack. Figure 2 shows a pile of felled bamboos gathered prior to mechanical testing.

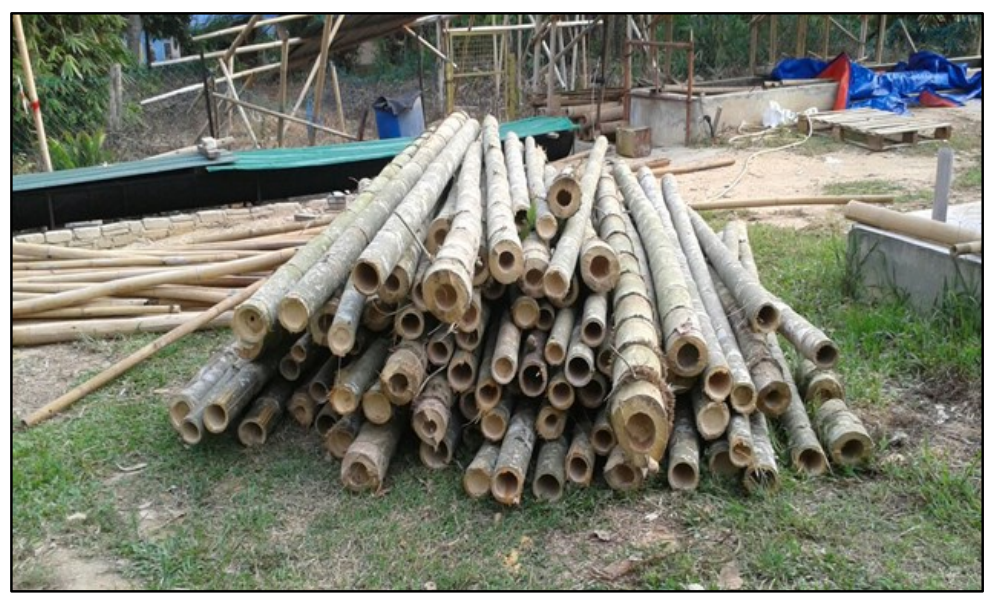

Fig.2 Four bamboo species

\subsection{Mechanical testing}

All bamboo species were cut into small samples, in which the samples were taken from the internode of the bamboo culm. Three tests have been involved in this research including, compression, tensile, and moisture content, in accordance with ISO 22157 Part 1 [14].

All specimens were cut from the bottom, middle, and top parts of the bamboo and marked with letters B, M, and T, respectively. For compression test and tensile tests, all specimen with free nodes were selected. The outer diameter of the bamboo specimen, $\mathrm{D}$, to be used for 
compression test was measured from two opposite points of the outer surface. The average diameter was recorded. Average wall thickness, $t$, of the bamboo culm was measured from four points, separated by a $90^{\circ}$ angle around the diameter of the specimen. Compression test was carried out by using a Universal Testing Machine, where the specimens for four bamboo species were tested under a constant rate of $0.01 \mathrm{~mm} / \mathrm{s}$, as shown in Figure 3. Maximum load for each specimen was recorded by using a data logger.

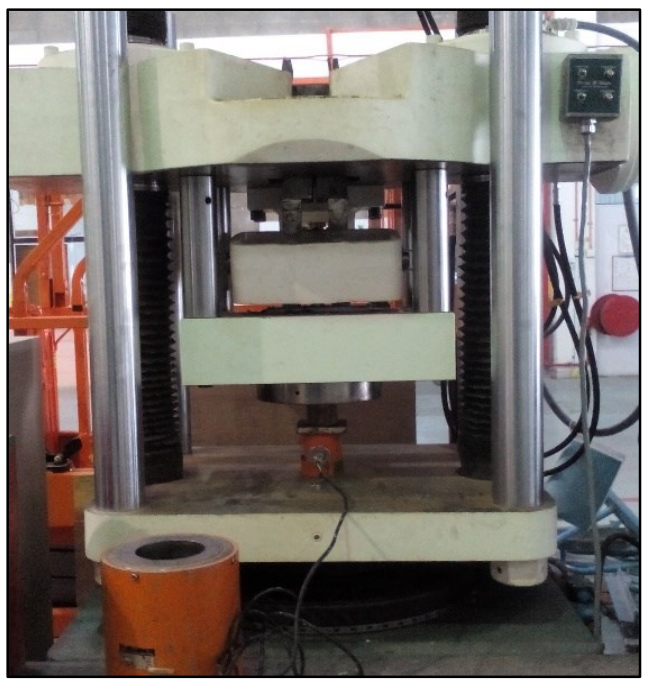

Fig 3. Bamboo specimen under compression test using Universal Testing Machine

Upon completion of compression test, small samples with a dimension of $25 \mathrm{~mm} \times 25 \mathrm{~mm}$, as shown in Figure 4 were taken and cut immediately from each bamboo species' specimen to undergo moisture content test. The samples were then weighed. Subsequently, they were dried in a hot air drying oven at $103 \pm 2^{\circ} \mathrm{C}$ for 24 hours. In order to quantify the amount of moisture content left after being dried in the hot air drying oven, the samples were weighed again and the weight was recorded.

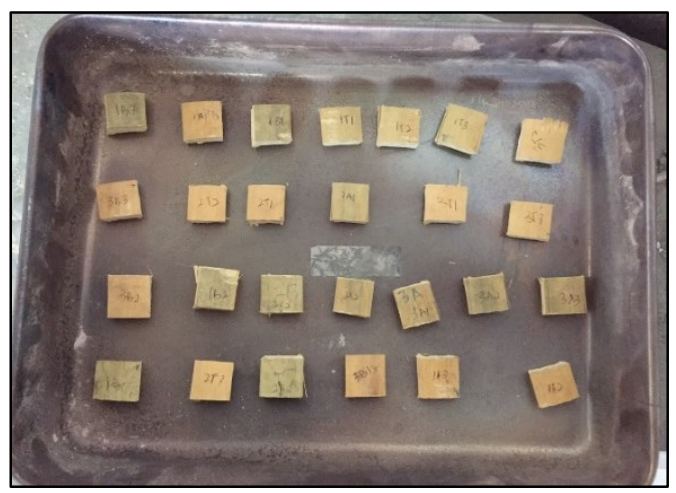

Fig 4. Specimens for moisture content test 
Standard tensile strength test as described in ISO 22157 Part 2 [15] directs that specimens should be cut into a 'dogbone' shape. The specimens in this study were cut radially from the culm wall, in order to produce a 'dogbone' shape. All of the specimens were cut and prepared parallel to bamboo's fibre. For testing the specimens' tensile strength, a $0.01 \mathrm{~mm} / \mathrm{s}$ load was applied gradually. The setup of the tension test, which was arranged parallel to bamboo's grain is shown in Figure 5.

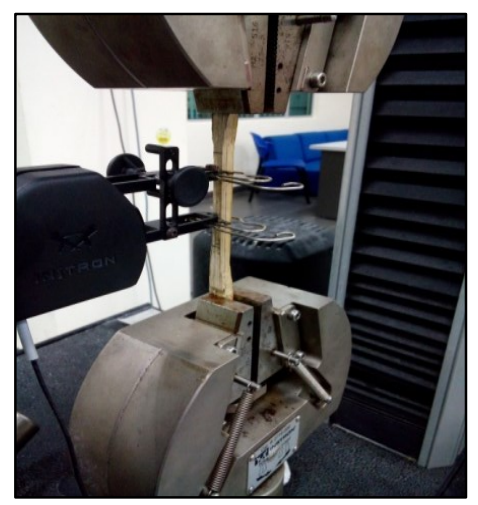

Fig 5. Tensile strength test setup

\section{Results and discussions}

\subsection{Compression test and moisture content}

Compressive strength and moisture content of bamboo specimens are reported in Table 1. The strength of each bamboo species' specimen was tested at a five-month interval in order to determine the strength development of the bamboo.

Table 1. Compressive strength and moisture content of bamboo

\begin{tabular}{|c|c|c|c|c|c|}
\hline Species & Part & $\begin{array}{c}\text { Average } \\
\text { Compressive } \\
\text { Strength }\left(1^{\text {st }}\right. \\
\text { Month) } \\
\left(\mathrm{N} / \mathrm{mm}^{2}\right)\end{array}$ & $\begin{array}{c}\text { Average } \\
\text { Moisture } \\
\text { Content } \\
(\%)\end{array}$ & $\begin{array}{c}\text { Average } \\
\text { Compressive } \\
\text { Strength }\left(5^{\text {th }}\right. \\
\text { Month) } \\
\left(\mathrm{N} / \mathrm{mm}^{2}\right)\end{array}$ & $\begin{array}{c}\text { Average } \\
\text { Moisture } \\
\text { Content } \\
(\%)\end{array}$ \\
\hline $\begin{array}{c}\text { Dendrocalamus } \\
\text { Asper }\end{array}$ & Top & 68.05 & 20.83 & 73.65 & 15.85 \\
\cline { 2 - 6 } & Middle & 61.34 & 20.57 & 59.84 & 17.91 \\
\cline { 2 - 6 } & Bottom & 60.23 & 18.32 & 53.08 & 18.44 \\
\hline Bambusa Vulgaris & Top & 76.52 & 15.29 & 78.74 & 14.01 \\
\cline { 2 - 6 } & Middle & 66.09 & 17.17 & 78.67 & 15.10 \\
\cline { 2 - 6 } & Bottom & 60.26 & 21.43 & 66.43 & 19.20 \\
\hline \multirow{2}{*}{$\begin{array}{c}\text { Gigantochloa } \\
\text { Scortechinii }\end{array}$} & Top & 69.02 & 16.09 & 68.62 & 15.60 \\
\cline { 2 - 6 } & Middle & 57.16 & 20.29 & 67.11 & 16.95 \\
\cline { 2 - 6 } & Bottom & 48.26 & 22.38 & 59.4 & 18.09 \\
\hline \multirow{2}{*}{$\begin{array}{c}\text { Schizostachyum } \\
\text { Grande }\end{array}$} & Top & 30.42 & 23.36 & 40.03 & 16.87 \\
\cline { 2 - 6 } & Middle & 28.32 & 19.67 & 31.70 & 17.98 \\
\cline { 2 - 6 } & Bottom & 27.05 & 20.44 & 25.77 & 19.63 \\
\hline
\end{tabular}


As reported in Table 1, the average compressive strength of bamboo was observed to be high at the top part of all bamboo species, followed by middle, and lastly, bottom part. The different values signify the different specimen locations where the specimens were cut. Specimens taken near the culm's base were slightly weak and older than the specimens that were taken far from the culm's base. The difference in this property is attributed to the presence of big vascular bundles that are present in bamboos. Vascular bundles are responsible for transporting all the nutrients from culm's base during the life of bamboos. These vascular bundles have indirectly resulted in a lower fibre content at the culm's base as compared the top part of the culm.

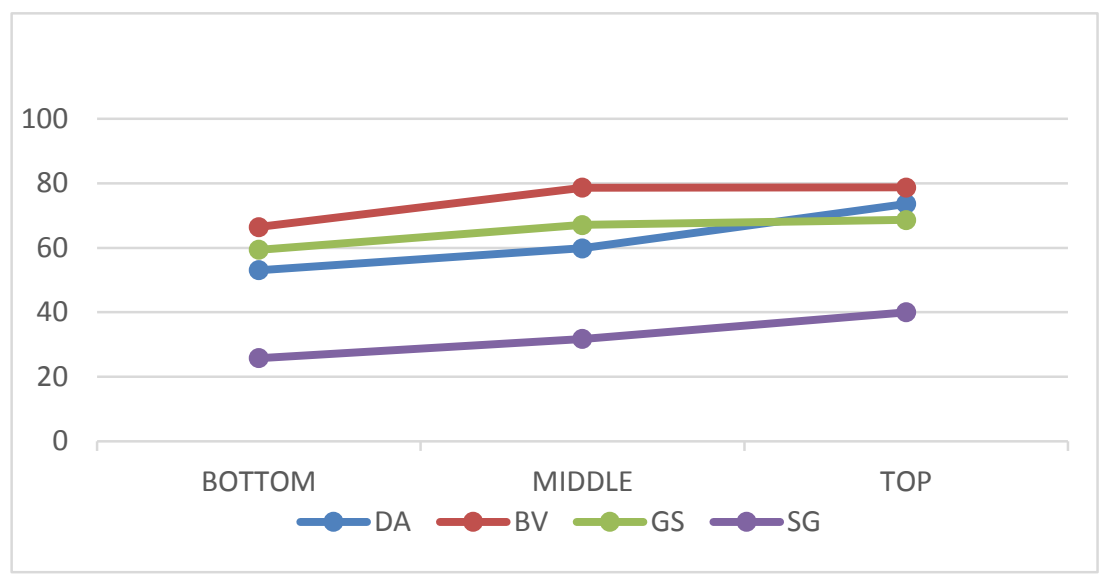

Fig 6. The difference compressive strength at bottom, middle and top.

After a five-month interval, a second compression test was conducted. The result showed a similar trend, whereby the top part of the culm possesses a high compressive strength as compared to middle and bottom parts. In moisture content test, after a five-month interval, the moisture content of bamboo specimens fell. This resulted in a higher compressive strength of the specimens as compared to one month old specimens. The moisture content of the specimens fell gradually, as all the specimens were kept in an air drying storage. As presented in Table 1, the moisture content of all four bamboo species' specimens ranges from $19.63 \%$ to the lowest moisture content, $14.01 \%$, which is two percent short from the desired optimum moisture content, $12.00 \%$.

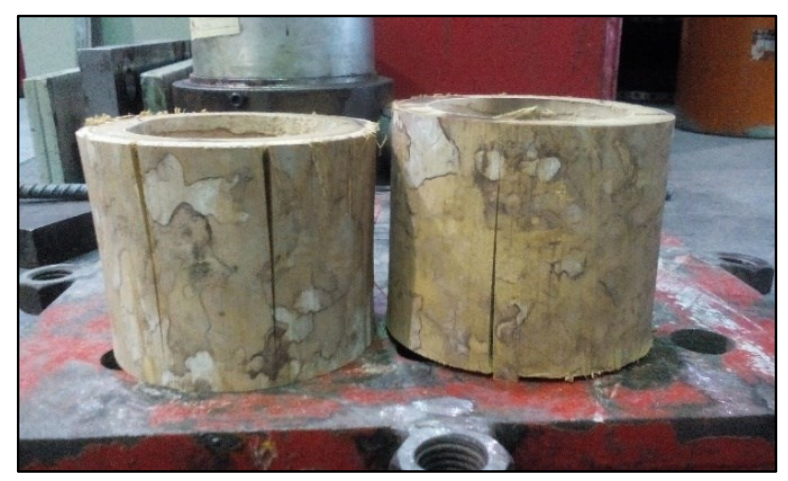

Fig 7. Vertical crack and end bearing failure of specimen after compression test 
Visual inspection on the specimens after compression test also revealed multiple cracks, which eventually led to splits as individual specimens' sections buckled. These vertical cracks are shown in Figure 7. From this figure, it is the evident that bamboos with air-dried culms experienced brittle failure.

\subsection{Tensile test}

Tensile strength test parallel to bamboo's grain was carried out in the same condition as compressive strength test, where the specimens used had undergone hot air drying. The result of the tensile test is shown in Table 2. Table 2 shows the tensile strength of Dendrocalamus Asper species. The average strength of Dendrocalamus Asper species is slightly lower at the middle part of the bamboo, while the strength at the top and bottom parts are almost equal, with recorded readings of 232.80 and $232.31 \mathrm{~N} / \mathrm{mm}^{2}$, respectively.

Table 2: Tensile strength of Dendracalamus Asper

\begin{tabular}{|c|c|c|c|c|}
\hline Part & Sample & Area $\left(\mathrm{mm}^{2}\right)$ & $\begin{array}{c}\text { Tensile Strength } \\
\left(\mathrm{N} / \mathrm{mm}^{2}\right)\end{array}$ & $\begin{array}{c}\text { Average Tensile } \\
\text { Strength } \\
\left(\mathrm{N} / \mathrm{mm}^{2}\right)\end{array}$ \\
\hline \multirow{3}{*}{ Top } & 1T & 98.68 & 262.47 & \multirow{2}{*}{232.80} \\
& 2T & 91.83 & 189.49 & \\
\cline { 2 - 4 } & 3T & 77.91 & 246.43 & \\
\hline \multirow{3}{*}{ Middle } & 1M & 99.45 & 275.51 & \multirow{2}{*}{200.75} \\
\cline { 2 - 4 } & 2M & 94.94 & 189.59 & \\
\cline { 2 - 4 } & 3M & 99.89 & 137.15 & \multirow{2}{*}{232.31} \\
\hline \multirow{3}{*}{ Bottom } & 1B & 119.20 & 289.43 & \\
\cline { 2 - 4 } & 2B & 114.504 & 153.71 & \\
\cline { 2 - 4 } & 3B & 105.19 & 253.82 & \\
\hline
\end{tabular}

Table 3 shows the tensile strength of Bambusa Vulgaris species, which recorded a strength of above $200 \mathrm{~N} / \mathrm{mm}^{2}$ across all parts of the bamboo considered in this study. The results show that Bambusa Vulgaris exhibits an almost similar tensile strength as Dendrocalamus Asper, with bamboo's top, middle, and bottom parts recorded readings of, 231.67, 233.98 and $230.63 \mathrm{~N} / \mathrm{mm}^{2}$, respectively.

Table 3. Tensile strength of Bambusa Vulgaris

\begin{tabular}{|c|c|c|c|c|}
\hline Part & Sample & Area $\left(\mathrm{mm}^{2}\right)$ & $\begin{array}{c}\text { Tensile Strength } \\
\left(\mathrm{N} / \mathrm{mm}^{2}\right)\end{array}$ & $\begin{array}{c}\text { Average Tensile } \\
\text { Strength } \\
\left(\mathrm{N} / \mathrm{mm}^{2}\right)\end{array}$ \\
\hline \multirow{3}{*}{ Top } & 1T & 56.00 & 246.71 & \multirow{2}{*}{231.67} \\
& 2T & 57.12 & 215.71 & \\
\cline { 2 - 4 } & 3T & 58.80 & 232.59 & \\
\hline \multirow{3}{*}{ Middle } & 1M & 60.90 & 237.32 & \multirow{2}{*}{233.98} \\
\cline { 2 - 4 } & 2M & 60.90 & 229.74 & \\
\cline { 2 - 4 } & 3M & 62.06 & 234.89 & \multirow{2}{*}{230.63} \\
\hline \multirow{3}{*}{ Bottom } & 1B & 68.48 & 233.45 & \\
\cline { 2 - 4 } & 2B & 67.20 & 210.31 & \\
\cline { 2 - 4 } & 3B & 65.92 & 248.13 & \\
\hline
\end{tabular}

For Gigantochloa Scortechinii, the recorded readings of tensile strength for top, middle, and bottom parts of bamboo are below $200 \mathrm{~N} / \mathrm{mm}^{2}$. The highest strength at the top part of the bamboo recorded a reading of $187.67 \mathrm{~N} / \mathrm{mm}^{2}$, while the bottom part recorded a reading of 
$176.22 \mathrm{~N} / \mathrm{mm}^{2}$. Meanwhile, middle part of the bamboo recorded a slightly lower reading than the bottom and top parts, with a reading of $144.92 \mathrm{~N} / \mathrm{mm}^{2}$. However, the difference is not significant. The tensile strength of Gigantochloa Scortechinii species is shown in Table 4.

Table 4. Tensile strength of Gigantochloa Scortechinii

\begin{tabular}{|c|c|c|c|c|}
\hline Part & Sample & Area $\left(\mathrm{mm}^{2}\right)$ & $\begin{array}{c}\text { Tensile Strength } \\
\left(\mathrm{N} / \mathrm{mm}^{2}\right)\end{array}$ & $\begin{array}{c}\text { Average Tensile } \\
\text { Strength } \\
\left(\mathrm{N} / \mathrm{mm}^{2}\right)\end{array}$ \\
\hline \multirow{3}{*}{ Top } & 1T & 50.00 & 190.19 & 187.67 \\
\cline { 2 - 4 } & 2T & 49.00 & 188.87 & \\
\cline { 2 - 4 } & 3T & 49.00 & 183.95 & \\
\hline \multirow{3}{*}{ Middle } & 1M & 47.00 & 153.36 & \multirow{2}{*}{144.92} \\
\cline { 2 - 4 } & 2M & 48.50 & 125.12 & \\
\cline { 2 - 4 } & 3M & 50.00 & 156.27 & \\
\hline \multirow{3}{*}{ Bottom } & 1B & 53.04 & 151.66 & \\
\cline { 2 - 4 } & 2B & 53.04 & 225.07 & \\
\cline { 2 - 4 } & 3B & 53.04 & 151.94 & \\
\hline
\end{tabular}

Lastly, Table 5 shows the tensile strength of Schizostachyum Grande species. The top part of this species shows the highest tensile strength reading as compared to its middle and bottom parts' readings. However, in comparison to other three bamboo species, Schizostachyum Grande shows the lowest recorded readings of tensile strength.

Table 5. Tensile strength of Schizostachyum Grande

\begin{tabular}{|c|c|c|c|c|}
\hline Part & Sample & Area $\left(\mathrm{mm}^{2}\right)$ & $\begin{array}{c}\text { Tensile Strength } \\
\left(\mathrm{N} / \mathrm{mm}^{2}\right)\end{array}$ & $\begin{array}{c}\text { Average Tensile } \\
\text { Strength } \\
\left(\mathrm{N} / \mathrm{mm}^{2}\right)\end{array}$ \\
\hline \multirow{3}{*}{ Top } & 1T & 47.43 & 156.71 & \multirow{2}{*}{149.20} \\
& 2T & 48.45 & 164.58 & \\
\cline { 2 - 4 } & 3T & 48.76 & 126.32 & \\
\hline \multirow{3}{*}{ Middle } & 1M & 48.88 & 110.36 & \multirow{2}{*}{114.93} \\
\cline { 2 - 4 } & 2M & 50.44 & 114.20 & \\
\cline { 2 - 4 } & 3M & 48.23 & 120.22 & \multirow{2}{*}{113.01} \\
\hline \multirow{3}{*}{ Bottom } & 1B & 50.35 & 97.71 & \\
\cline { 2 - 4 } & 2B & 49.4 & 102.34 & \\
\cline { 2 - 4 } & 3B & 48.76 & 138.97 & \\
\hline
\end{tabular}

Figure 8 shows failures of specimens taken from tensile test. Most of the specimens experienced similar mode of failure, which comprised of the combination of tension and shear parallel to grain. This mode of failure is different as compared to timber, which has rays and knots that cause it to withstand less stress through the length of stalk. 


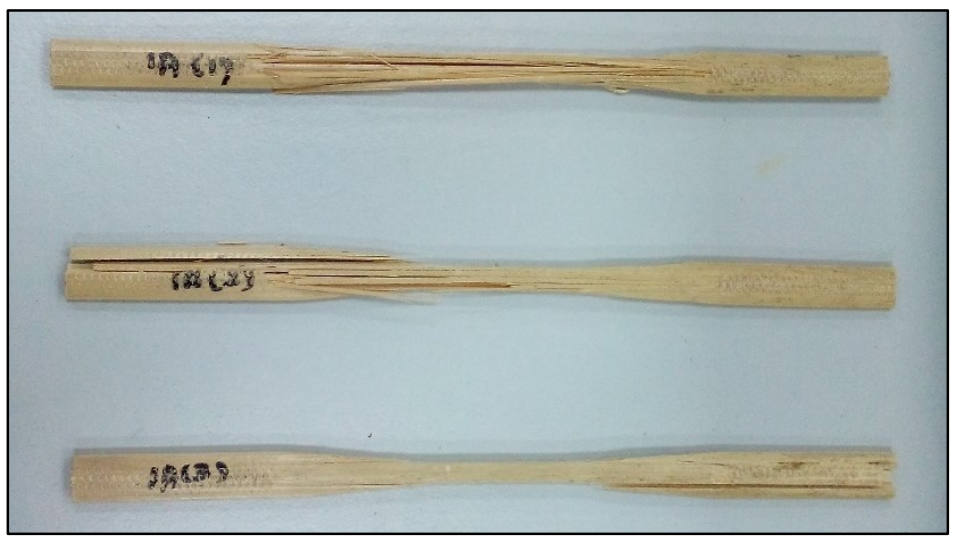

Fig 8. Mode of failure on tensile specimens

Based on previous research findings, bamboos show a good performance in strength properties as compared to other materials such as wood and steel. Table 6 shows the comparison of strength properties of spruce wood, steel, and bamboo [16]. Bamboo possesses higher compressive and tensile strengths when compared with spruce wood, but lower when compared with steel.

Table 6. Comparison of strength properties of bamboo with other materials

\begin{tabular}{|c|c|c|c|}
\hline Materials & $\begin{array}{c}\text { Compressive Strength } \\
\text { or Yield Strength } \\
\left(\mathrm{N} / \mathrm{mm}^{2}\right)\end{array}$ & $\begin{array}{c}\text { Tensile Strength } \\
\left(\mathrm{N} / \mathrm{mm}^{2}\right)\end{array}$ & $\begin{array}{c}\text { Elastic Modulus } \\
\left(\mathrm{N} / \mathrm{mm}^{2}\right)\end{array}$ \\
\hline Spruce Wood & 43 & 89 & 11000 \\
\hline Steel & 250 & 410 & 21000 \\
\hline $\begin{array}{c}\text { Treated Bamboo } \\
\text { (Bambusa Vulgaris) }\end{array}$ & 78 & 233 & 20000 \\
\hline
\end{tabular}

\section{Conclusions}

The present study indicates that bamboo has a promising potential to be used as a construction material. The findings also indicate that the utilization of bamboo should be practiced widely. In the study, compression, tensile, and moisture content tests were conducted to test four bamboo species' ability and capability. Following a five-month interval, the compressive strength of all bamboo species had increased due to degraded moisture content. In addition, all bamboo species exhibited a good performance in tensile strength test. From the overall result of mechanical testing, Dendrocalamus Asper and Bambusa Vulgaris species endured the highest compression and possess the highest tensile strength, followed by Gigantochloa Scortechinii and Schizostachyum Grande species. Thus, the experimental results revealed that bamboo has a good performance in strength properties.

This research was supported by a basic science research program through Research University Grant (RUG) (No.Q.J130000.2522.13H01), with the funding from the Ministry of High Education (MOHE) and Universiti Teknologi Malaysia. This research was also supported by the National Research Foundation (NRF) of Korea, with the funding from the Ministry of Science, ICT, and Future Planning 
(No. 2015R1A5A1037548). The authors wish to express their utmost gratitude to these funding entities, which have allowed the research endeavour to be carried out.

\section{References}

1. Q. Xu, K. Harries, X. Li, Q. Liu, and J. Gottron, "Mechanical properties of structural bamboo following immersion in water," Eng. Struct., 81, 230-239, (2014).

2. K. F. Chung and W. K. Yu, "Mechanical properties of structural bamboo for bamboo scaffoldings," Eng. Struct., 24, no. 4, 429-442, (2002).

3. W. Liese, "Research on bamboo," Wood Sci. Technol., 21, no. 3, 189-209, (1987).

4. B. Sharma, A. Gatoo, M. Bock, H. Mulligan, and M. Ramage, "Engineered bamboo: state of the art," Proc. ICE - Constr. Mater., no. April, 1-11, (2014).

5. L. Yiping, L. Yanxia, K. Buckingham, G. Henley, and Z. Guomo, "Bamboo and climate change mitigation : a comparative analysis of carbon sequestration," no 32, 47, (2010).

6. A. Syeda, B. Shrujal, and J. Kumar, "A case study on bamboo as green building material," no 2, 78-82, (2014).

7. M. R. Wakchaure and S. Y. Kute, "Effect of moisture content on physical and mechanical properties of bamboo," Asian J. Civ. Eng. (Building Housing), 13, no. 6, 753-763, (2012).

8. Chinese Standard Agency. Testing methods for physical and mechanical properties of bamboo used in building. JG.T199-2007; (2007).

9. K. Ghavami, "Bamboo: Low cost and energy saving construction materials," Int. Conf. Mod. Bamboo Struct., no. January 2008, (2008).

10. Janssen, J.J.A. 1985. The machanical properties of bamboo. Resent Research in Bamboo. Proceeding of the International Bamboo Workshop Hangshou, China. Oct. 6-14, (1985).

11. Kabir, M.F., Bhattacarjee, D.K. \& Sattar, M.A. Physical and mechanical properties of four bamboo species. Bangladesh Journal of Forest Science, 20, pp 31-36, (1991).

12. Lavers, C.M. The strength properties of timber. Forest Product Research Bulletin. no. 5, 62,(1969).

13. Sattar, M.A., Kabir, M.F. \& Bhattacharjee, D.K. Effect of age and height position of muli (Melocanna baccifera) and borak (Bambusa balcooa) on the physical and mechanical properties. Bangladesh Journal Forestry Science, 19 (1 and 2), 29-38, (1990).

14. ISO/TR. 22157-1, "Bamboo - Determination of physical and mechanical properties Part 1: Requirement," 2004, 1-8, (2004).

15. ISO/TR 22157-2, "Bamboo - Determination of physical and mechanical properties Part 2: Laboratory Manual," 2004, 28, (2004).

16. T. Gutu, "A Study on the Mechanical Strength Properties of Bamboo to Enhance Its Diversification on Its Utilization,” no. 5, 314-319, (2013). 